\title{
Megacolon tóxico
}

\section{Toxic megacolon}

\author{
Agustín Güemes Quinto, ${ }^{*}$ Dahiana A Pichardo Cruz, ${ }^{*}$ Luis Enrique Bolaños Badillo*
}

Citar como: Güemes QA, Pichardo CDA, Bolaños BLE. Megacolon tóxico. Acta Med. 2021; 19 (1): 144-145. https://dx.doi.org/10.35366/98591

Masculino de 52 años de edad, con antecedente de diabetes tipo 2 de larga evolución. Recibió tratamiento antibiótico para infección de tejidos blandos secundaria a herida por objeto punzocortante. Es hospitalizado por cuadro de tres días con diarrea y posteriormente oclusión intestinal. A la exploración encontramos paciente pálido, taquicárdico, con dificultad respiratoria, aumento del perímetro abdominal y dolor. Presenta leucocitosis de 17,000 y glucosa en $285 \mathrm{mg} / \mathrm{dL}$. Prueba de toxinas A/B positiva. Los estudios de imagen revelan datos de megacolon tóxico (Figuras 1 a 3). Se decide intervención quirúrgica urgente donde observamos distensión extensa del colon (Figura 4). Se realizó colectomía total con ileos- tomía terminal. El reporte histopatológico reveló colitis pseudomembranosa.

El megacolon tóxico es una complicación poco frecuente y potencialmente mortal de la colitis infecciosa y de la enfermedad inflamatoria intestinal caracterizada por dilatación colónica total o segmentaria secundaria a sepsis. ${ }^{1,2}$ La incidencia por Clostridioides difficile se ha elevado actualmente debido al uso desmedido de antibióticos de amplio espectro. ${ }^{3,4} \mathrm{El}$ uso de vancomicina y/o metronidazol vía oral o intravenoso está indicado en todos los casos. La colectomía total más ileostomía es el procedimiento quirúrgico de elección cuando falla el tratamiento conservador. ${ }^{5,6}$

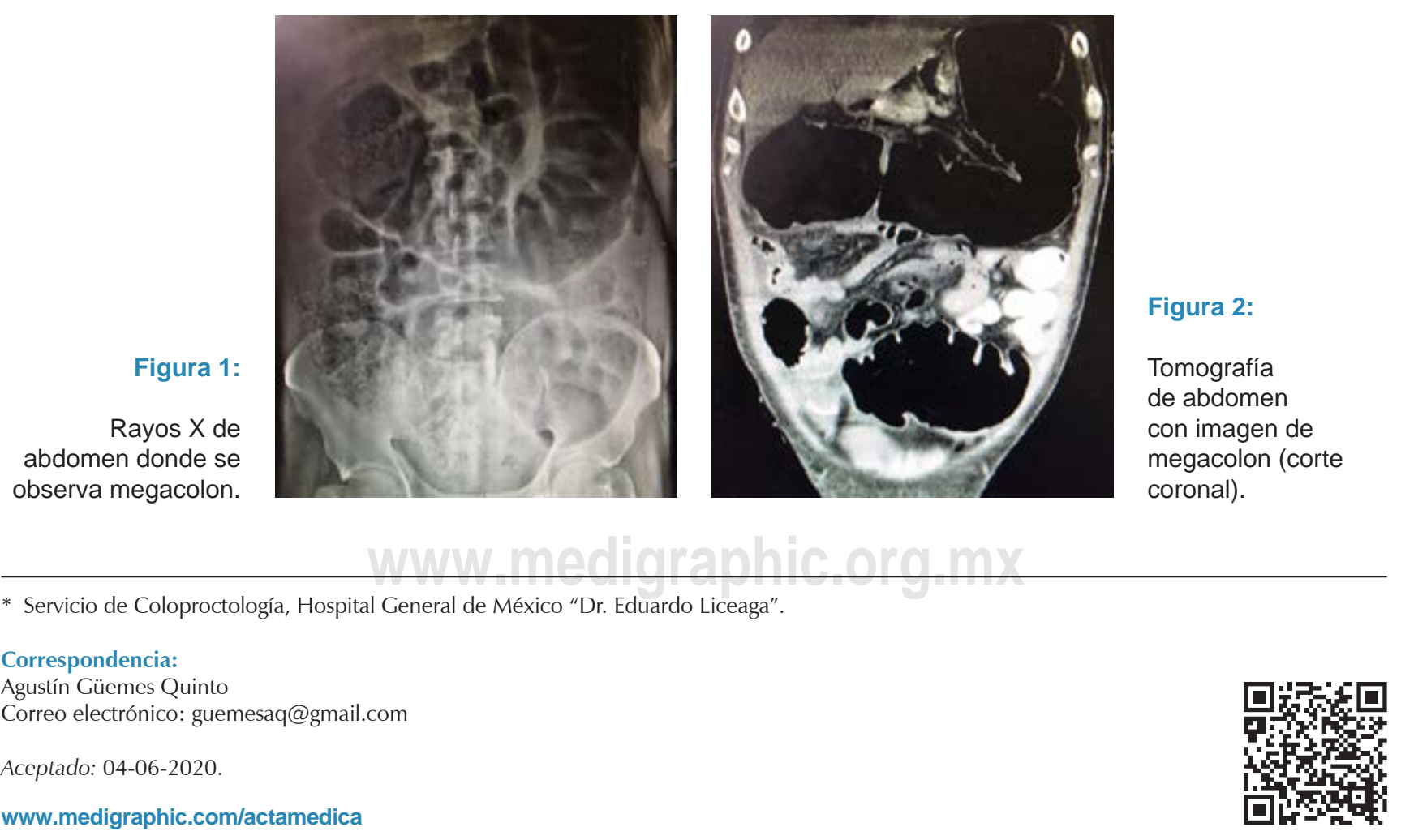




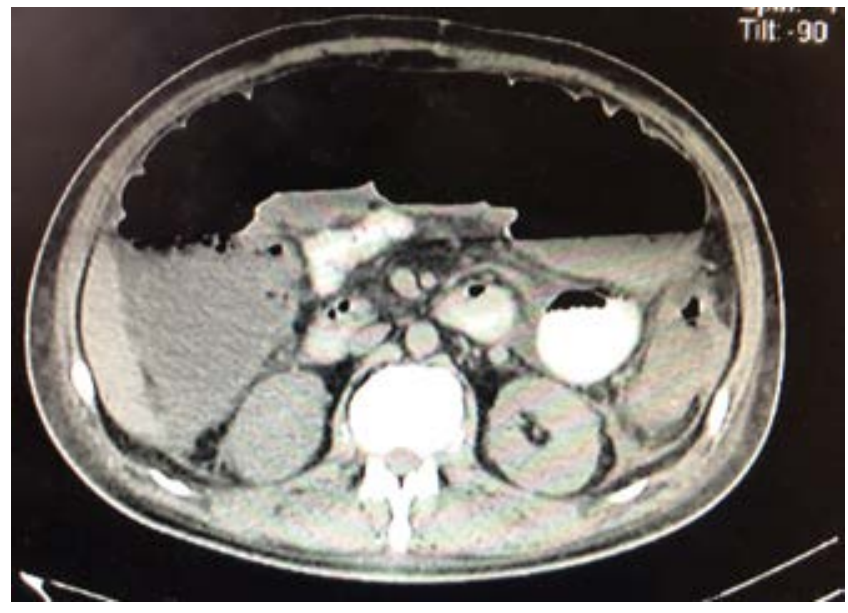

Figura 3: Tomografía de abdomen con imagen de megacolon (corte axial).

\section{REFERENCIAS}

1. Carrillo-Esper R, Calderon-Álvarez Tostado JL, Muciño-Bermejo J, Ramírez-Rosillo F. Megacolon tóxico. Med Int Mex. 2012; 28 (1): 282-287.

2. Ausch C, Madoff RD, Gnant M, Rosen HR, Garcia-Aguilar J, Hölbling $\mathrm{N}$ et al. Aetiology and surgical management of toxic megacolon. Colorectal Dis. 2006; 8 (3): 195-201.

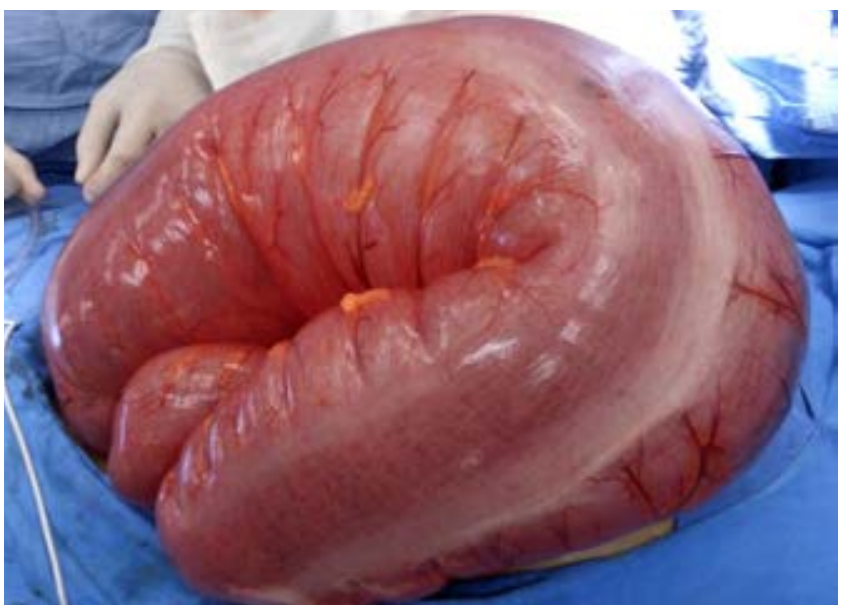

Figura 4: Imagen de megacolon durante el transoperatorio.

3. Zilberberg MD, Shorr AF, Kollef MH. Increase in adult Clostridium difficile-related hospitalizations and case-fatality rate, United States, 2000-2005. Emerg Infect Dis. 2008; 14 (6): 929-931.

4. Gan SI, Beck PL. A new look at toxic megacolon: an update and review of incidence, etiology, pathogenesis, and management. Am J Gastroenterol. 2003; 98 (11): 2363-2371.

5. Anderson M, Grucela A. Toxic megacolon. Semin Colon Rectal Surg. 2019; 30: 1-4.

6. Strong SA. Management of acute colitis and toxic megacolon. Clin Colon Rectal Surg. 2010; 23 (4): 274-284. 